\title{
La comprensión auditiva en inglés como lengua extranjera. De la metacognición a la competencia comunicativa
}

\author{
JOAMSNER MAGDALENA ARÉVALO \\ Universidad Nacional Experimental Francisco de Miranda \\ Smartkelly1912@gmail.com
}

\section{Resumen}

El desarrollo de las destrezas orales (hablar y escuchar) en el contexto de una lengua extranjera tiene un mayor grado de dificultad para los aprendices, pues al no estar inmersos en el contexto natural del idioma no están expuestos a caudal lingüístico auténtico y continuo que los haga avanzar en su competencia comunicativa (Brown, 2014). En este sentido, la comprensión auditiva es de gran importancia, pues si no se es capaz de alcanzar una comprensión cabal de la información que se provee no se podrá producir una interacción coherente del aprendiz con sus semejantes. Partiendo de esta premisa se condujo una investigación experimental orientada a caracterizar el desempeño de los estudiantes en la unidad curricular electiva Comprensión Auditiva. En esta, se instruye a los aprendices en las características de la comprensión y particularidades del discurso oral y se propicia la metacognición y autorregulación, de manera que al estar conscientes de sus procesos puedan crear sus propias oportunidades de aprendizaje fuera del aula, incrementando así su contacto con la lengua extranjera. Así pues, se llevó a cabo un estudio que contó con una población de 17 estudiantes del sexto semestre de la carrera de Educación Mención Inglés de la Universidad Nacional Experimental Francisco de Miranda. Los resultados arrojaron que posterior a la culminación de la unidad curricular el grupo alcanzó niveles evaluativos y responsivos (Wolvin, 2010) de comprensión, lo cual finalmente incidía positivamente en su competencia comunicativa.

\section{Palabras clave}

Comprensión auditiva, metacognición, competencia comunicativa, inglés. 


\title{
Listening Comprehension in English as a Foreign Language. From Metacognition to the Communicative Competence
}

\begin{abstract}
The development of oral skills (speaking and listening) in the context of a foreign language has a greater degree of difficulty for learners, because as they are not immersed in the natural context of the language they are not exposed to authentic and continuous input that makes them move forward in their communicative competence (Brown, 2014). In this sense, listening comprehension is of great relevance because if someone is not able to reach a complete understanding of the input that is provided, it will not be possible to produce a coherent interaction with peers. Based on this premise, an experimental investigation was conducted aimed at characterizing the students' performance in the elective course, Listening Comprehension. In this course, students are trained in the characteristics of the comprehension and particularities of the oral discourse, but also metacognition and self-regulation are encouraged, so that by being aware of their processes they can create their own learning opportunities outside the classroom, thus increasing their contact with the foreign language. This study was carried out counting on a population of 17 students of the sixth semester of the career of Educación Mención; Inglés at the Universidad Nacional Experimental Francisco de Miranda. The results showed that after the culmination of the course the group reached critical and responsive levels of comprehension (Wolvin, 2010), which finally had a positive effect on their communicative competence.
\end{abstract}

\section{Keywords}

Listening comprehension, Metacognition, Communicative Competence, English.

Recibido el 22/03/2018

Aceptado el 21/01/2019 


\section{Introducción}

Es innegable la relevancia que tiene el manejo básico del inglés para el progreso eficiente en cualquier terreno laboral, puesto que este idioma domina diversos campos de investigación e innovación de modo que se hace de suma importancia su uso competentemente en sus cuatro destrezas, hablar, escuchar, escribir y leer. En este sentido, cuando se dice que un individuo es comunicativamente competente, se hace referencia a su capacidad de transmitir mensajes coherente y cohesivamente, de manera eficaz usando las destrezas de las que dispone.

Chomsky (2006), indicó que la competencia no era más que el conocimiento que se tiene sobre el uso del lenguaje. Este autor realizó una diferenciación entre los términos «competence»y «performance». La primera se refiere a las nociones alusivas al lenguaje y lo segundo, es decir el «performance», se refiere a la producción real. El término se puede traducir como actuación; aquello que podemos percibir cuando el emisor pone en práctica su competencia, el comportamiento lingüístico de quien formula un mensaje.

Entonces, un aprendiz de lengua extranjera posee un conjunto de conceptos almacenados que pone en práctica cuando produce un texto oral o escrito. Este conjunto de conceptos no es estático, sino que perfeccionándose en la medida que se recibe más información sobre el idioma, esto es lo que Krashen (2009) llamó el comprehensible input o «i $+1 »$. Recientemente, Lee (2018) ha reforzado la teoría de Krashen describiendo que el avance de un estudiante en su nivel de competencia depende de poder recibir información en la lengua extranjera que esté llena de significado real, que provenga de situaciones auténticas y que lo obligue a usar su conocimiento previo para construir los nuevos conceptos. De este modo, usando el conocimiento que ya tiene y dará el paso adelante que lo lleve a la comprensión, y así situarse en un nuevo nivel de competencia. Para esto también es importante que esa información entrante (comprehensible input) sea genuina, producida por hablantes nativos del idioma y que venga por diferentes vías y formatos.

Es relevante mencionar que el contexto de enseñanza juega un papel importante en la forma y cantidad de información y materiales que se brindan a un estudiante de idiomas. Así pues, en el contexto de lengua extranjera las oportunidades para acceder a material auténtico son limitadas y en muchos casos restringidas al aula de clase (Brown, 2014). Adicionalmente, la mayor parte de la información de la que se dispone viene de 
forma escrita, mientras que los textos orales son más escasos, lo que trae como consecuencia que el nivel de comprensión auditiva de un hablante extranjero no se desarrolle a la par de su comprensión lectora.

Gilakjani y Sabouri (2016), indicaban que la audición es de hecho el canal más usado en el proceso de asimilación exitosa de información nueva de un idioma, pero contradictoriamente esta destreza es la más ignorada durante el proceso de enseñanza - aprendizaje. Los mismos autores resaltan que la destreza auditiva era erróneamente concebida como pasiva, pero extensas investigaciones en el campo han venido a corregir esa percepción señalando la serie de procesos de análisis y negociación de significados que ocurren para lograr la comprensión del texto oral.

En efecto, la comprensión auditiva tiene características particulares; pues mientras que un lector puede ir y venir en un texto cuantas veces sea necesario hasta lograr su total comprensión, la información oral suele venir "en vivo" durante una interacción con los semejantes y con frecuencia requiere una respuesta inmediata. Respuesta esta que, para que pueda ser adecuada, necesita que el texto recibido haya sido correctamente decodificado, analizado e interpretado.

Al respecto Rost (2011), dice que dentro del acto de recibir información por vía oral existe primero una orientación receptiva donde se toma el mensaje tal y como es expresado. Seguidamente se toma la información contenida en los esquemas del oyente y a partir de ella se construye y representa el significado en una orientación constructiva. Hecho esto, dentro de la orientación colaborativa se negocia el significado con el receptor y se emite una respuesta que finalmente, a través de la orientación transformativa de la comprensión, queda impregnada de las creencias y experiencias de este.

La comprensión auditiva es, entonces, un proceso complejo y vital, particularmente dentro del contexto del aprendizaje de una lengua extranjera. Evidentemente, si el estudiante no logra alcanzar un nivel apropiado de comprensión de la información no será capaz de usarla para avanzar en su aprendizaje. Aun así, con frecuencia los alumnos no suelen estar conscientes de este hecho ni de su propio proceso de comprensión, no conocen las variables envueltas en él y en esa medida dependen grandemente del profesor para crear situaciones de aprendizaje, pues el mencionado desconocimiento los incapacita para crearlas por ellos mismos fuera del aula.

Con esto en mente se trae a colación el concepto de metacognición, que no es más que «el conocimiento de los procesos mentales envueltos en los diferentes tipos de 
aprendizaje» (Richards y Schmidt, 2013. p. 361). Este concepto se refiere directamente al hecho anterior, al hablar del conocimiento que los estudiantes tienen o no tienen acerca de todo lo relativo a su instrucción, a como se desarrolla su propia comprensión y manejo de un nuevo idioma, a como se apropian de las nuevas habilidades y competencias hasta dominarlas.

Según Goh (2018), la instrucción metacognitiva viene a ser aquel tipo de enseñanza que va orientada a brindarle al individuo las herramientas que necesitará para jugar un rol más activo dentro de su propio acto de enseñanza y aprendizaje. Se apunta a entrenarlo para que esté al tanto de cada uno de los pasos que sigue para ser competente en una destreza y pueda procurarse todas las actividades, materiales, insumos y condiciones que lo lleven a un aprendizaje exitoso.

En este sentido, se llevó a cabo una investigación de tipo experimental en la que se describió y evaluó el desempeño de un grupo de diecisiete (17) estudiantes en la unidad curricular electiva Comprensión Auditiva. Esta tiene como fin desarrollar las destrezas auditivas del estudiante desde el punto de vista de la metacognición y autorregulación, para que así pueda no solo comprender de manera efectiva textos orales en el inglés, sino que sea capaz de crear, por sí mismo, condiciones que lo mantengan en contacto constante con el idioma dentro y fuera del aula, asegurando el desarrollo de una alta competencia comunicativa. Cabe destacar que esta unidad curricular se basa en el enfoque de contenido al seleccionar las unidades temáticas que posean una relación directa con la cultura del inglés presentando a los alumnos materiales auténticos lo más parecido posible al contexto natural, en el que no se hacen concesiones de significado (Harmer, 2008).

El estudio se llevó a cabo durante el semestre 1-2017 de la Licenciatura en Educación Mención: Inglés de la Universidad Nacional Experimental Francisco de Miranda (UNEFM) en la ciudad de Coro, en Venezuela. Siguiendo una metodología en la que se expuso a la población a todas las variables midiendo su desempeño y respuesta a las mismas en el período especificado.

Habiendo dicho esto, se hace necesario desarrollar los conceptos que sirvieron de soporte en el tránsito por la investigación y que dieron forma a los resultados. 


\section{La competencia comunicativa en comprensión auditiva}

Peris (1972 citado en Córdoba, Coto y Ramírez, 2005) indica que la comprensión auditiva es una destreza, es decir una habilidad lingüística que el estudiante de lengua extranjera puede mejorar a medida se exponga al idioma que pretende aprender. Es en efecto, una destreza activa, que consiste en desarrollar la interpretación de un mensaje a través de técnicas y tácticas propias del receptor.

En este orden de ideas, la palabra más importante en este proceso es la comprensión, y es que se debe ser capaz de entender, interpretar, y usar la información que se recibe. Anderson y Lynch (2003) hablaban de las etapas que transita el individuo durante su proceso de decodificación del texto. De acuerdo con estos autores, el individuo percibe el mensaje en el ambiente, lo categoriza y discrimina aquello que no forma parte del él. Esta clasificación se ayuda del tipo de procesamiento de abajo hacia arriba o "Bottom-up" en el que se perciben los componentes individuales del texto. A partir de esto, se analiza la información y se le asigna significado, combinando el procesamiento de abajo hacia arriba y de arriba hacia abajo o Top-down. Referido este último al análisis general que se hace del mensaje viendo la imagen completa en lugar de los componentes individuales (Brown, 2014). En este punto es importante el conocimiento previo del receptor, pues entre mayor sea el repertorio de este más fácilmente se comprenderá el mensaje.

Habiendo decodificado e interpretado exitosamente el mensaje, se espera que el receptor pueda hacer algo con este. En palabras de Anderson y Lynch (2003.), que lo utilice, que sea capaz de producir una respuesta que no necesariamente debe ser verbal, sino que puede consistir en una acción, un gesto o un cambio de comportamiento.

Los planteamientos de Rost (2011), vienen a reforzar lo enunciado anteriormente, cuando describe lo que denominó las orientaciones dentro del proceso de comprensión auditiva; es decir la orientación receptiva, constructiva, colaborativa, y transformativa. Explicaba Rost, que durante la interacción se construye y representa el significado de los sonidos recibidos pasando por una negociación con el emisor para seguidamente producir una respuesta que inevitablemente transforma el mensaje, que queda impregnado de las creencias y el comportamiento del receptor.

Ahora bien, el estudio de los procesos de comprensión auditiva en el aprendizaje y enseñanza de lenguas extranjeras se centra en el papel de las unidades lingüísticas individuales (fonemas, palabras, unidades gramaticales), así como en el de las 
expectativas de los oyentes, la situación y el contexto. En otras palabras, la interacción de los procesamientos Top-down y Bottom-Up. A pesar de esto, los enfoques tradicionales de enseñanza tienden a subestimar la importancia de la compresión auditiva, pues se asume que los intercambios con el profesor y los compañeros dentro del aula, a través de fórmulas establecidas y patrones fijos, es suficiente. Enfoques recientes hacen hincapié en el papel que la habilidad auditiva tiene en el desarrollo de la competencia comunicativa y sugieren que se debe prestar más atención a ella, sobre todo en las etapas iniciales del aprendizaje de una lengua extranjera (Schmidt, 2013).

La competencia comunicativa en la comprensión auditiva implica no sólo la verdadera decodificación y comprensión del texto oral, sino ser capaz de hacer algo con el mensaje. Significa decir algo, realizar una acción, cambiar un comportamiento. Berko, Wolvin, Wolvin y Aitken (2016) afirman que escuchar es un acto conductual y, al igual que otros actos conductuales, puede mejorarse con la práctica y la retroalimentación. Sin duda, el que escucha emplea el conocimiento y la acción. Por citar un ejemplo, si un individuo escucha un saludo puede responder a él empleando exactamente la misma palabra que recibió y eso es socialmente aceptable. Del mismo modo, si otra persona entra a una habitación señalando que "It's too hot!" quien recibe el mensaje podría dirigirse silenciosamente a encender el aire acondicionado y eso también sería una respuesta perfectamente válida, aunque en el primer caso se emite una respuesta verbal y en la segunda la respuesta es conductual.

En realidad, la comprensión auditiva está involucrada en casi todas las actividades diarias, razón por la cual es trascendental para el desarrollo de una verdadera competencia comunicativa; pero en el caso particular del aprendizaje de una lengua extranjera hay pocas oportunidades de practicar esta destreza fuera del aula, simplemente porque la lengua extranjera no es el principal medio de comunicación en el entorno natural del estudiante. Por lo tanto, los profesores deben ocuparse de motivar y capacitar a su audiencia para crearse tantas oportunidades de contacto con el idioma extranjero como sea posible. Y es que, las habilidades receptivas (escuchar y leer) son las que en última instancia habilitarán a las habilidades productivas (hablar y escribir), permitiendo que se asimile el mensaje significativamente.

Cabe hacer un alto y acotar que cuando se habla de escuchar se habla de recibir información, datos, significados que vienen de alguien que busca establecer un contacto; se habla de interactuar y toda interacción tiene un propósito. Así, cuando se pide a un aprendiz que se rodee de situaciones de interacción en la lengua extranjera, 
cada una de estas situaciones debe tener un propósito claro y relevante. En este orden de ideas, no está de más señalar que se distinguen dos propósitos principales por los cuales se decide aprender una lengua extranjera. Dichos propósitos son instrumentales o de placer.

Los propósitos instrumentales hacen alusión a aquellas situaciones en las que la lengua extranjera se usa con el objetivo de completar una tarea específica que probablemente se enfoca en obtener una información precisa. Son situaciones que ocurren en marcos laborales o académicos, en los que el aprendiz debe cumplir con las expectativas o peticiones de otro actor, entiéndase un jefe, profesor o compañero. Por otro lado, cuando la exposición al idioma ocurre con fines de placer las personas tratan principalmente de disfrutar la actividad, aunque puedan ser conscientes de que esta les ayudará a mejorar su competencia comunicativa. Escuchar música, ver una película o hablar con amigos también podrían tener un propósito instrumental, porque sirven para ejercitar las competencias, pero al estar libres de la presión de cumplir con una asignación lo que priva es la espontaneidad y la naturalidad que gobierna las situaciones de comunicación auténticas (Harmer, 2015).

Estos dos aspectos no son mutuamente excluyentes, de hecho pueden ir de la mano y en realidad deben ser puestos en práctica en el aula de manera unificada cuando se practican todas las destrezas del lenguaje. Es la combinación de estos dos propósitos lo que estimula y apoya el uso de material auténtico en la enseñanza de la comprensión auditiva. El material auténtico es ese que muestra situaciones reales de comunicación, conducidas por hablantes nativos, y que exhibe los sonidos del lenguaje tal y como se encuentran en la vida real. Estos materiales incluyen frases idiomáticas y coloquiales que no siempre se pueden encontrar en entornos académicos, pero que su conocimiento es importante si se quiere alcanzar una buena competencia comunicativa.

Por ejemplo, con frecuencia los estudiantes no perciben ciertos fonemas ingleses con exactitud porque estos no existen en su lengua materna. Sonidos como los de «think», o secuencias y yuxtaposiciones en la línea de los grupos de consonantes en las palabras «parts» o «little», por mencionar algunos (Ur, 2013). Lo que llevará a un estudiante a dominar estos fonemas y a ser comunicativamente competentes en su uso será únicamente la exposición constante a ellos a través del material auténtico.

En los últimos años se ha demostrado con suficiente evidencia que la práctica del lenguaje en aislamiento es ineficaz y va contra su propósito natural. La comprensión auditiva debe ser enseñada teniendo en cuenta el verdadero propósito de escuchar. La 
gente escucha con un objetivo en mente, de ahí que los estudiantes necesitan sentir que tienen un objetivo real dentro de sus actividades y no simplemente la diferenciación de sonidos. Sean estos propósitos instrumentales o de placer, el discurso debe presentarse en el contexto de una interacción que ponga al grupo en la posición de hablantes, donde el punto de escuchar es usar la información como lo haría en la vida real. En tales circunstancias no importa si se han comprendido o no todos los detalles individuales de lo que se dijo; lo que importa es que, en el contexto de la tarea, han sido capaces de construir una interpretación razonable y que emitan una respuesta exitosa, tal y como se hace incluso en la lengua materna.

El principal objetivo de la comprensión auditiva es pues comprender, y a partir de allí crear nuevos conocimientos y modificar comportamientos. Alcanzar la tan mencionada competencia que al traducirse en la actuación permita al usuario del lenguaje conectarse con su entorno. Para que esto ocurra el oyente debe alcanzar un nivel alto de comprensión, es decir, debe poder decodificar los sonidos y asumir una postura ante el mensaje. Sobre estos niveles de comprensión han disertado varios autores cuyos conceptos se revisarán a continuación.

\subsection{Niveles de comprensión auditiva}

Un estudiante de inglés necesita experimentar una comprensión significativa para alcanzar la competencia comunicativa y, a su vez, tener un desempeño adecuado. En el apartado anterior se trató sobre la competencia comunicativa en la comprensión auditiva y se señaló que, además de las etapas por las que transita el oyente cuando recibe información vía oral, este también recorre una serie de niveles de comprensión para llegar a adueñarse de dicha información, tomar postura frente a ella, interpretarla de manera significativa y emitir una respuesta.

A propósito de esto, estudios anteriores como los de Galvin (1988) distinguían tres niveles de comprensión auditiva. El nivel transaccional, en el cual el alumno recibe la información o mensaje vía oral, el nivel interpretativo que implica la decodificación de lo que se escucha en base al conocimiento previo, y finalmente el nivel evaluativo en el que se emiten juicios críticos y valorativos sobre el mensaje. Como se puede apreciar, en esta clasificación no se toma en cuenta el uso de la información para generar respuestas conductuales, de hecho, se puede establecer un paralelismo directo con los 
niveles de comprensión lectora, literal, inferencial y crítico; establecidos, entre otros, por Alliende y Condemarín (1986).

Entonces, el receptor de la información decodifica, interpreta y evalúa, pero en este proceso queda un vacío, un espacio donde el mensaje debe generar algo. La información que se recibe tiene un fin, busca una reacción inmediata. Es esta la naturaleza, y una de las diferencias fundamentales entre la interacción oral y la escrita, la respuesta inmediata y perceptible en forma de acción. Con la escritura la respuesta conductual, si es que se produce, viene en diferido; quien emite la información no suele estar presente para recibir o percibir las respuestas producto de su escrito.

La interacción oral es un intercambio de enunciados y respuestas. Respuestas que si bien vienen de una decodificación, interpretación y evaluación, como lo dijo Galvin (1988.), van un paso más allá. Con respecto a esto, Wolvin (2010), propuso cuatro niveles de procesamiento del texto oral. El primer nivel coincide en denominarlo transaccional y tiene lugar cuando se emiten los enunciados. Aquí se inicia el intercambio de información y el receptor toma el mensaje (sonido) y procede a decidir qué hacer con él. En segundo lugar, el nivel interpretativo permite al individuo activar su conocimiento previo y relacionarlo con la información entrante, haciendo inferencias y añadiendo un poco de sí mismo al mensaje. En el contexto del aprendizaje de una lengua extranjera, estos dos primeros niveles tienen mucha relevancia, pues implican usar el conocimiento que el oyente tenga del vocabulario y del contexto de la interacción.

Efectivamente, el aprendiz de inglés puede llegar a experimentar una especie de retroceso en su comprensión del discurso oral cada vez que entra en contacto con una comunidad de hablantes, con un nuevo acento o cuando aborda un tópico con cuyo vocabulario no está familiarizado. Esto ocurre porque el individuo no tiene esquema suficiente para descifrar y negociar el significado. Se explica así por qué para los estudiantes es más fácil comprender lo que dice el profesor, a quien se escucha con frecuencia y con quien comparte el mismo acento y velocidad de producción del discurso; que entender a un hablante nativo.

Habiendo superando los dos primeros niveles, el individuo procede a evaluar el mensaje. En el nivel evaluativo se analiza la información dada, configurando una respuesta basada en la conexión realizada en los niveles anteriores. Aquí es donde se fija posición y se toman las decisiones que conducen al último nivel de comprensión o nivel responsivo. 
Innegablemente, es este último nivel el que refleja que en efecto se llegó a la comprensión. La adecuación o relevancia de la respuesta puede enriquecer o entorpecer la comunicación, reflejando una comprensión exitosa o defectuosa. Todo esto debe ser considerado al diseñar las estrategias y actividades de comprensión auditiva, orientándose a promover la escucha intensiva y extensiva como recurso para asegurarse que los aprendices estén en contacto con el idioma dentro y fuera del aula, y que el tipo de actividades que realicen sean lo más parecidas posible a la interacción real.

\subsection{Escucha extensiva e intensiva}

Con el fin de promover actividades de comprensión auditiva fuera del aula, el profesor de lengua extranjera puede animar a los aprendices a participar en actividades de escucha extensivas e intensivas. Durante la escucha extensiva, los estudiantes eligen por sí mismos el material y lo hacen siguiendo propósitos de placer y por el mejoramiento general del lenguaje (Harmer, 2015). Los materiales para la escucha extensiva se pueden encontrar ahora en numerosas fuentes, desde vídeos de YouTube, películas, hasta música o cualquier otro, siempre y cuando se asegure que el acto sea tanto auténtico como agradable.

El hecho clave de la escucha extensiva es que se realiza fuera del aula y que se percibe como una actividad placentera. El individuo puede saber que es una actividad asignada en clase, pero no siente ninguna presión u obligación porque puede hacerla durante su tiempo libre. Sin embargo, el maestro debe crear un sistema para monitorear estas actividades, no tanto para asegurar que se está haciendo como para mantener un registro de la mejora del estudiante en su destreza auditiva (Brown, 2017). Grupos de discusión antes o después de la clase, donde los estudiantes digan lo que han escuchado, tarjetas de comentarios donde puedan escribir el nombre, nivel de dificultad y un resumen del material usado son algunas maneras fáciles de mantener un seguimiento del grupo sobre las actividades.

En el contexto específico de este estudio, se emplearon sesiones de discusión al final de cada clase y se les pidió a los estudiantes que llevaran un registro tanto de la actividad que realizaron (ver un video o película, escuchar música, podcasts o la radio) como de su experiencia en general, y de las estrategias que emplearon para alcanzar un 
apropiado nivel de comprensión auditiva, en concordancia con las recomendaciones de Goh (2018).

Por otra parte, la escucha intensiva se realiza dentro del aula, en forma de podcasts, videocasts, entrevistas o conversaciones, donde no necesariamente hay materiales auténticos (Harmer, 2015). Este tipo de actividades mayormente siguen propósitos instrumentales, y a fin de hacerlas más efectivas se necesita tener una tarea y metas claras, para que los participantes sepan lo que van a hacer con la información y por qué es importante hacerlo. Ur (2013) explica que se necesita involucrar a los aprendices en actividades lo más parecidas a la vida real y esto puede implicar, por ejemplo, usar recursos completamente novedosos en cada sesión y no emplear repeticiones del material durante la ejecución de las actividades. Esto se hace con el fin de que los estudiantes sientan la necesidad de usar las mismas estrategias que utilizarían en una interacción real, en las que el hablante no está constantemente repitiendo el mensaje para asegurar que lo entiendan. En fin, que las tareas que se diseñan deben ser concebidas de manera que propicien respuestas espontáneas como se harían en la vida cotidiana.

Algunas desventajas de la escucha intensiva tienen que ver con la calidad de los recursos utilizados para reproducir los materiales, así como las características del aula y el tamaño del grupo, que pueden causar interferencia durante el proceso de audición. Además, en un gran grupo de estudiantes se pueden encontrar diferentes niveles de competencia, por lo que algunos de ellos pueden estar bien escuchando los materiales sólo una vez, como ocurriría en una situación de la vida real, pero otros podrían necesitar más que eso. Por lo tanto, los profesores necesitan estar preparados para cualquiera de estas situaciones.

Formar a los estudiantes para que estén conscientes de sus procesos y de lo que necesitan hacer para lograr un alto nivel de comprensión auditiva y una apropiada competencia comunicativa. Es aquí donde la metacognición y la autorregulación juegan un papel de vital importancia, como se explicará seguidamente.

\subsection{Metacognición y autorregulación}

La audición es una destreza con frecuencia sub valorada por ocurrir, en condiciones normales, de manera automática sin necesidad de instrucción o siquiera de modelamiento. Sin embargo, cuando se trata de la comprensión auditiva en una lengua 
extranjera, los oyentes deben comenzar a ser conscientes de su proceso, si quieren apoderarse completamente del mensaje y dar una respuesta apropiada que vaya acorde con sus propósitos y los deseos del hablante.

No se trata simplemente de saber cómo aproximarse a un mensaje oral usando una perspectiva Bottom Up o Top Down, o tener noción de a través de cuales etapas o niveles transita el individuo cuando se enfrenta a un mensaje oral, se trata en verdad de que la persona sea capaz de tomar control de su propia cognición y en cierto sentido dosificar, según sus necesidades, los pasos por lo que debería transitar para resolver un problema. Eso es lo que se llama metacognición y autorregulación (Hernández e Izquierdo, 2016).

Con respecto a esto, Escorcia (2010) afirma que en el concepto de metacognición pueden agruparse todos aquellos conocimientos sobre los procesos intelectuales que toman a la cognición como objeto y que regulan un aspecto determinado de su funcionamiento. Así pues, dentro de la metacognición se puede encontrar dos componentes fundamentales, los conocimientos metacognitivos y la autorregulación. Según Richards y Schmidt (2013) los conocimientos metacognitivos se refieren a la comprensión de los procesos mentales envueltos en los diferentes tipos de aprendizaje, a través de esta, los aprendices se vuelven conscientes de sus propia cognición, lo que incluye reconocer cuáles tipos de tareas causan dificultad, cuáles enfoques funcionan mejor que otros a la hora de recordar la información y cómo ir resolviendo los desequilibrios de aprendizaje más eficazmente.

Los conocimientos metacognitivos abarcan, en el plano personal, las habilidades y debilidades específicas del aprendiz. Por ejemplo, reconocer cuáles sonidos o acentos les cuesta más comprender. Seguidamente se tienen los conocimientos metacognitivos relativos a la tarea, aquellos que versan sobre las exigencias y características de la actividad que se va a realizar sea esta una actividad de práctica dirigida por el profesor dentro del aula o simplemente una conversación en la lengua meta entre compañeros. Finalmente se tienen los conocimientos metacognitivos de las estrategias, en estos se contempla el estar conscientes de cuáles son pertinentes o no en base al objetivo y el propósito que se tenga en la comprensión del texto oral (Brown, 2014; Campo, Escorcia, Moreno y Palacios, 2016).

Al hacer que los alumnos desarrollen su metacognición se les capacita para autorregularse, es decir, para que puedan echar mano de sus estrategias en el momento en que las necesiten; a la vez que también se les da el poder para auto controlarse y 
abordar cualquier situación comunicativa en la lengua extranjera. Para Zimmerman (1998 citado en Escorcia, 2010: 267) la autorregulación se trata de «un conjunto de estrategias que permiten al sujeto transformar el curso de su acción».

Esta autoregulación puede ocurrir a nivel interno cuando se logra el dominio de los factores emocionales relativos al idioma, tales como la ansiedad o el miedo al error. También puede ocurrir a nivel del comportamiento observable, cuando se asumen acciones específicas que garanticen la completa comprensión del mensaje; estas acciones pueden ser dirigidas a activar el conocimiento previo, por ejemplo. Finalmente la autorregulación puede estar orientada a preparar el contexto en el que se va a realizar la tarea, cosas como minimizar la interferencia del ambiente en el mensaje o usar las herramientas adecuadas durante la actividad.

Dentro del contexto del objeto de este estudio, la electiva de Comprensión auditiva busca precisamente activar en el estudiante su capacidad para usar sus conocimientos metacognitivos para autorregularse durante la realización de actividades de escucha extensiva e intensiva y así puedan hacerse cargo de incrementar su nivel de comprensión auditiva, lo que por consiguiente los llevará a incrementar su nivel de competencia comunicativa.

\section{Procedimiento de investigación}

\subsection{Metodología}

El procedimiento se condujo tomando en cuenta los objetivos propuestos en el marco del curso electivo de comprensión auditiva, dictado en la licenciatura en Educación Mención Inglés de la UNEFM, los cuales establecen primeramente que: los estudiantes deben ser capaces de «conocer y manejar los conceptos y características más relevantes del procesamiento de la información contenida en textos orales en Inglés». Seguidamente se expone que deben dominar las destrezas para: «reflexionar y aplicar el conocimiento sobre las estrategias de comprensión auditiva al procesamiento de la información contenida en textos orales en Inglés» (Arévalo, 2016: 4). Se puede apreciar cómo se abarcan aspectos fundamentales con respecto a la metacognicón y la autorregulación, como lo son el conocimiento de los procesos, la reflexión sobre los mismos y la aplicación de estrategias. 
Es importante acotar que, la población objeto de estudio estuvo conformada por 17 estudiantes de la unidad curricular durante el semestre 1-2017. Según el perfil de la carrera, este curso electivo está disponible a partir del sexto semestre, en esta fase los estudiantes estarían ubicados en un nivel avanzado de manejo del inglés, sin embargo como se pudo comprobar durante el transcurso de la investigación, los mismos presentan fallas en la comprensión auditiva del idioma.

A través de la realización de un diagnóstico se determinó que gran parte de las deficiencias que presentan los estudiantes en su comprensión auditiva se deben principalmente a la poca exposición que tienen a información auténtica en la lengua extranjera. A su vez, las razones de la falta de exposición a dicha información son de diversa índole; por un lado están las limitantes naturales que existen al enseñar un idioma en el contexto de lengua extranjera y por otro se encuentran aquellas relativas a la falta de recursos audiovisuales dentro del aula de clase. Todo esto se suma a la importancia de capacitar metacognitivamente a los aprendices para recrear espacios de exposición al idioma autónomamente fuera del recinto universitario.

En este orden de ideas, el diagnóstico consistió en una serie de ejercicios divididos en tres partes. La primera fue escuchar un podcast sobre la cultura popular de Sherlock Holmes en Londres y responder cinco preguntas de forma oral a partir de información reflejada explícitamente en el podcast. En la segunda parte el grupo debió ver el extracto de un noticiero norteamericano, en el cual se comentaba sobre la influencia de las redes sociales en la formación de matrices de opinión, para luego comentarlo en una discusión grupal abierta. Es de importancia detallar que ambos materiales eran auténticos, en el caso del podcast se trató con Inglés Británico, mientras que en el video se escuchó a hablantes de Inglés Americano, y en ambos casos solo escucharon el material una vez.

Finalmente, a modo de cierre, en la tercera parte del diagnóstico se les pidió a los estudiantes que hablaran de las dificultades que tuvieron para comprender ambos materiales, a qué se deben tales dificultades según su experiencia y qué acciones aplicarían para superarlas, en sintonía con las afirmaciones de Goh (2018).

Así pues del total de la muestra de 17 estudiantes 11 alcanzaron un nivel transaccional de comprensión, es decir recibieron el mensaje, distinguieron sonidos del idioma pero fallaron en hacer la conexión con sus conocimientos previos que los llevaría a interpretar el mensaje, evaluarlo y emitir las respuestas que se requerían en la actividad. El resto del grupo, seis estudiantes, pudieron hacer inferencias con respecto al mensaje, evaluarlo y llegar al nivel responsivo de comprensión (Tabla 1). 
Tabla 1: Diagnóstico

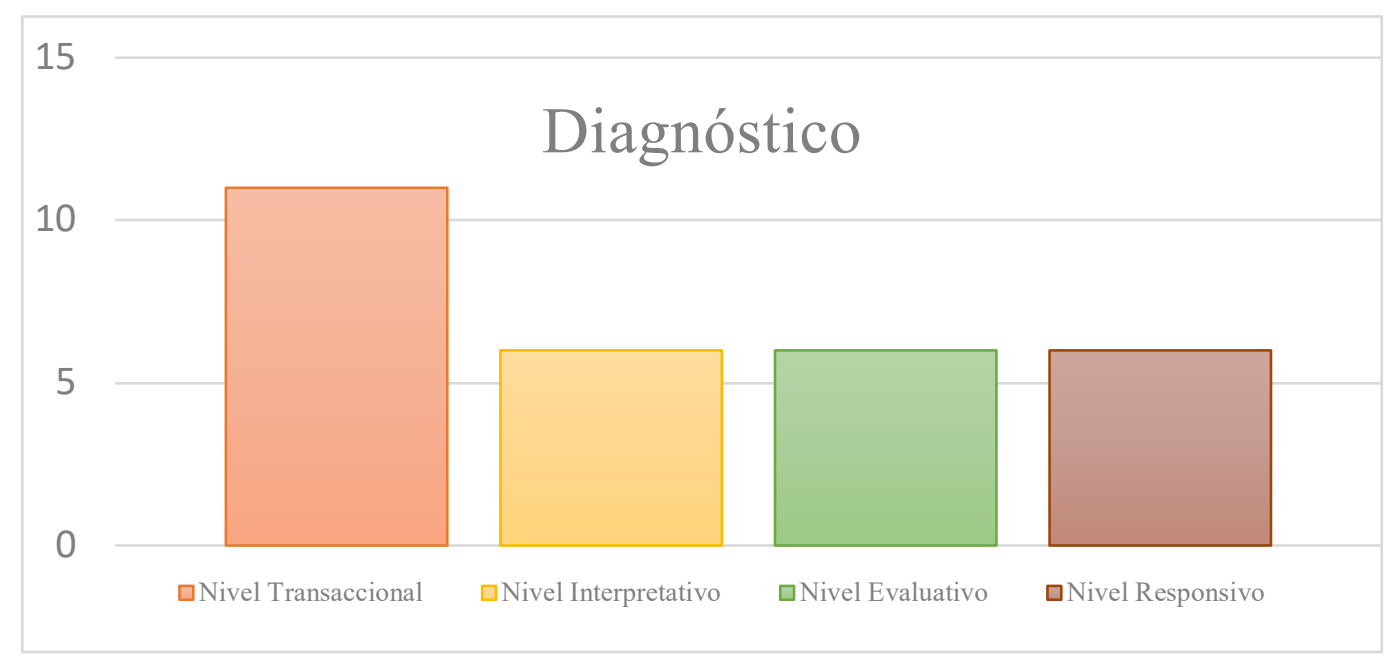

Al consultar al grupo sobre las razones de su ejecución la totalidad de los estudiantes manifestó estar consciente de su bajo nivel y expresaron que la razón es que dedican muy poco tiempo a ejercitar la audición en inglés. Esto trae como consecuencia que al enfrentarse a un ejercicio de comprensión auditiva experimenten ansiedad y no sepan qué estrategias aplicar para emitir respuestas correctas. Como dato importante se debe puntualizar que, según testimonio del grupo, el material que se les dificultó más comprender fue el usado en la primera parte de los ejercicios, es decir el de Sherlock Holmes por ser en Inglés Británico, pues según ellos mismos, en las ocasiones en las que ejercitan su audición en inglés escuchan con más frecuencia el Inglés Americano.

A partir de esta data se implementó una serie de 12 sesiones de escucha extensiva en las que los estudiantes debían escuchar materiales auténticos en inglés por espacio de mínimo 4 horas a la semana, en su tiempo libre. Estos materiales podían ser películas, series, música o cualquiera de su preferencia (ninguno de los cuales debía tener subtítulos). Al terminar cada sesión los participantes debían llenar una ficha de diario especificando la naturaleza y características del material, su opinión personal respecto al mismo y las dificultades (en caso de que las hubiese) que tuvieron en su comprensión (Fig. 1). 


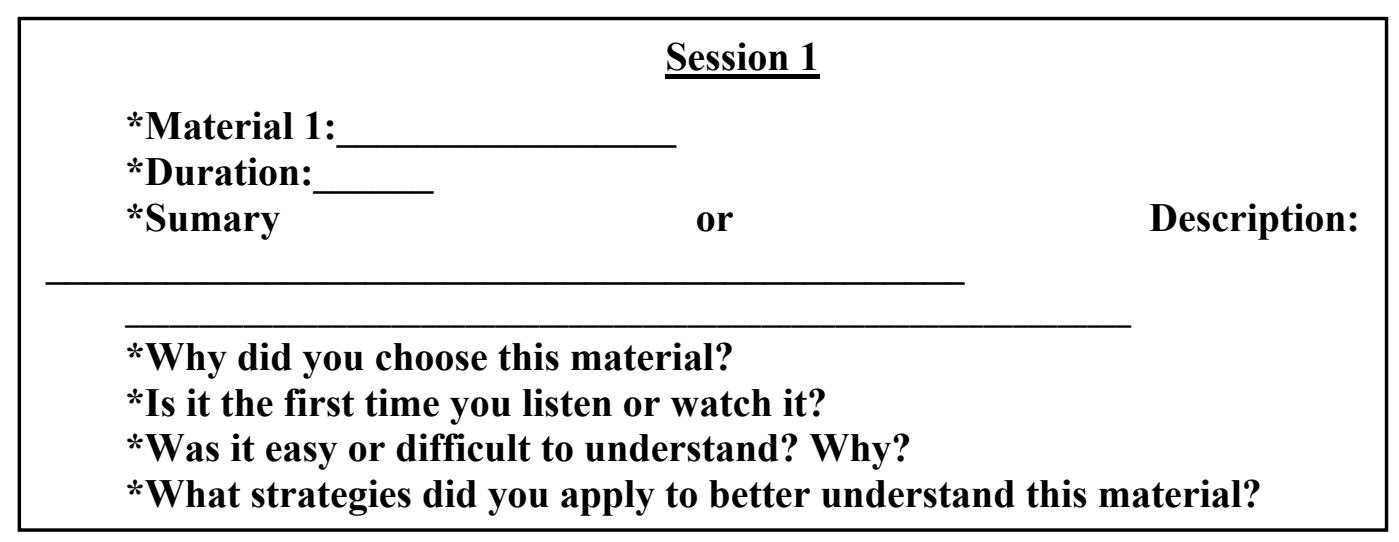

Figura 1: Ficha de Diario

A manera de cierre de cada se sesión se conformó un grupo de discusión al final de las clases de la asignatura, siguiendo las pautas presentes en la ficha de diario. En dicho grupo los estudiantes debían compartir y discutir sus experiencias con el resto de los compañeros con el fin de nutrirse con los procesos y las vivencias de los semejantes, al tiempo que al hablar y socializar sus propias estrategias se activara la toma de consciencia que es base de la metacognición y autorregulación, tal como lo expone Brown (2017).

En el transcurso de las 12 sesiones que se extendieron durante la duración del semestre 1-2017, el cual fue de 16 semanas, se fue evaluando en el aula el progreso de los estudiantes con ejercicios de escucha intensiva. Adicionalmente al grupo de discusión, que ya es en sí una actividad de escucha intensiva, se emplearon otros ejercicios como entrevistas, paneles de discusión y mesas redondas en inglés sobre los componentes de la destreza auditiva y los procesos cognitivos de la comprensión. Este tipo de estrategias concuerdan con lo expresado por Campo et. al. (2016), Ur (2013) y Harmer (2008); pues recrean una interacción real al tiempo que promueven la reflexión metacognitiva.

Al finalizar las 12 sesiones de entrenamiento con la escucha extensiva se llevó a cabo una actividad configurada de la misma manera que la actividad diagnóstica variando solo la naturaleza de los materiales. En este caso, en la primera parte se vio un video sobre las expresiones idiomáticas más usadas en Australia, después del cual se debían responder preguntas literales (cuyas respuestas están indicadas explícitamente en el video) en forma oral sobre la misma. En la segunda parte se vio el primer capítulo de una serie norteamericana (This is Us) sobre el que los estudiantes debían dar su 
opinión, hacer predicciones con respecto a la trama y contar lo que ellos harían de estar en la posición de los personajes.

Concluidas estas dos partes se le pidió al grupo que realizaran dos actividades. Primeramente debían evaluar su propio progreso con respecto a la actividad diagnóstica en una discusión abierta en clase, esto con el fin de promover la autoevaluación y el monitoreo. Seguidamente debieron realizar un relato escrito en el que describieran los pasos que siguieron para superar las primeras dificultades y que planes tenían para continuar aplicando este tipo de actividades de escucha extensiva al culminar el semestre, todo esto sustentado con por la teoría estudiada en clase (Hernández e Izquierdo, 2016).

\section{Resultados y discusión}

El resultado más relevante de este estudio sin duda queda reflejado en el incremento de la competencia comunicativa en la comprensión auditiva de los estudiantes.Se plantea que a mayor nivel de comprensión mejor nivel de competencia comunicativa. En comparación con el resultado del diagnóstico; en el que 11 de 17 estudiantes no alcanzaron un nivel interpretativo, evaluativo ni responsivo de comprensión, al finalizar las 12 sesiones de escucha extensiva 15 de 17 estudiantes pudieron tomar la información, interpretarla, evaluarla y responder efectivamente durante las actividades. Esto, en consecuencia, se reflejó en su nivel de competencia comunicativa y rendimiento académico (Tabla 2).

\section{Tabla 2: Evaluación Final}

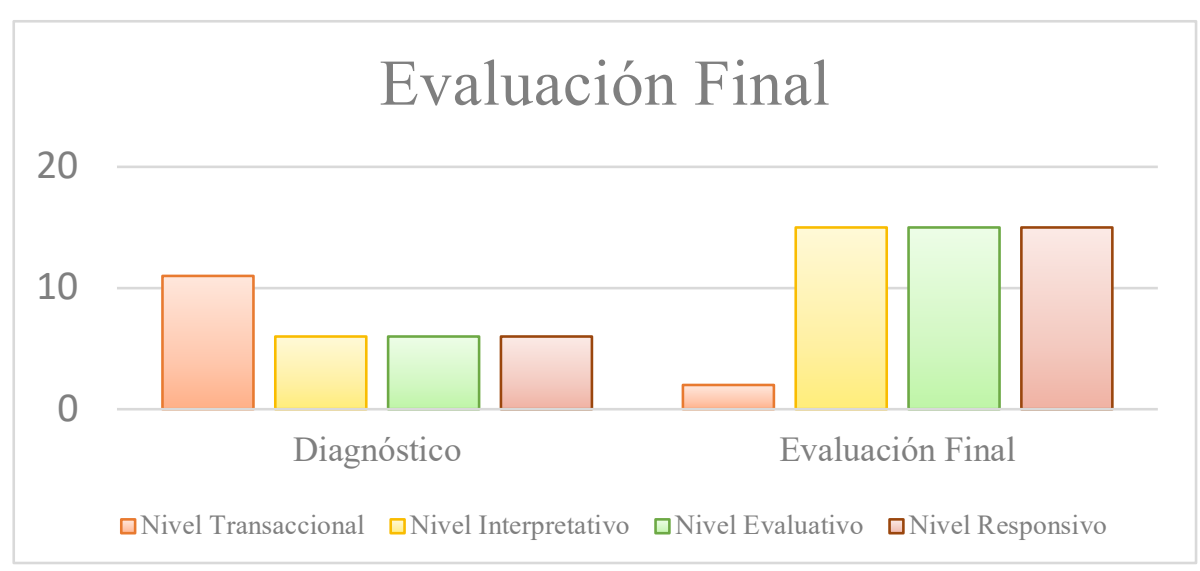


No está de más acotar que, los dos estudiantes del grupo que no consiguieron incrementar su competencia en relación al diagnóstico no siguieron las pautas dictadas para la realización de las actividades y tuvieron un alto nivel de inasistencias a clase.

Con respecto al primer objetivo de la asignatura, se pudo constatar que 15 de los 17 estudiantes de la asignatura alcanzaron un nivel alto de manejo de los "conceptos y características más relevantes del procesamiento de la información contenida en textos orales en Inglés" (Arévalo, 2016: 4). Tal conducta quedó en evidencia al aumentar su nivel de destreza auditiva y demostrar dominio metacognitivo y autorregulado de su comprensión al planear, monitorear, identificar el elemento problemático en cada actividad y evaluar la mejor estrategia para superar tal elemento a lo largo de las 12 sesiones de entrenamiento (Hernández e Izquierdo, 2016).

Cumplido el objetivo anterior, naturalmente se avanza al siguiente, pues al manejar las nociones teóricas se puede ser capaz de "reflexionar y aplicar el conocimiento sobre las estrategias de comprensión auditiva" (Arévalo, 2016: 4). Campo et. al. (2016) indican que precisamente la reflexión metacognitiva sirve para, de alguna manera, guiar la cognición del individuo hacia lo que necesita hacer en el modo y momento que necesite hacerlo (Tabla 3).

Tabla 3: Objetivos de la Asignatura

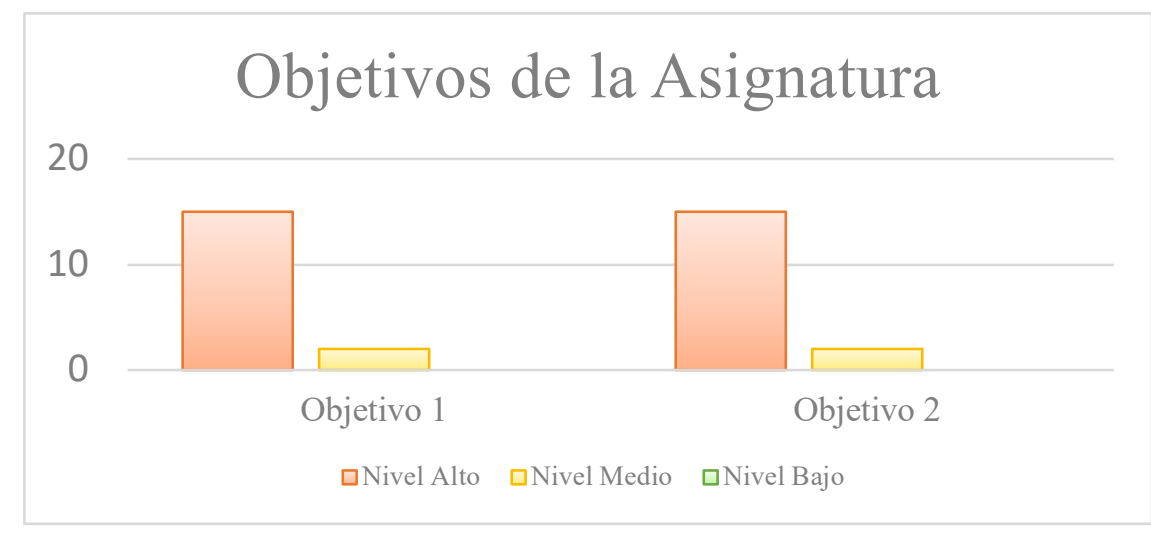

Culminado el semestre, el grupo manifestó en su relato escrito estar más preparado para continuar involucrándose en este tipo de actividades de escucha extensiva, con el fin de mantenerse ejercitando sus destrezas. Estas afirmaciones del grupo coinciden con los postulados de Brown (2017), pues las actividades al ser placenteras pueden mantenerse como práctica habitual en el tiempo. Los participantes, también manifestaron que antes de ver una película o documental sobre temas desconocidos 
para ellos se detienen a investigar un poco sobre el tema, igualmente al encontrarse con un dialecto o acento nuevo se enfocan en el mensaje en general para deducir el significado de las palabras individuales, y se preocupan por buscar más material con ese dialecto y acento para familiarizarse más con el mismo.

Al realizar estas actividades están tomando el control reflexivo de su proceso de aprendizaje, tal y como lo explica Escorcia (2010). Los alumnos crean un desequilibrio cognitivo al buscar intencionalmente enfrentarse a situaciones fuera de su nivel, pero paralelamente, al desarrollar su metacognición, están preparados para tomar medidas que reequilibren la situación, obteniendo como resultado un avance en su competencia comunicativa.

\section{Conclusiones}

Habiendo analizado los resultados se concluye que la metacognición es uno de los elementos de mayor peso en el desarrollo de la competencia comunicativa en la destreza auditiva. El desarrollo de la metacognción es altamente beneficioso pues permite mantener bajo control las estrategias más idóneas de acuerdo al estilo de aprendizaje de cada individuo haciendo más efectivo el aprendizaje de la lengua extranjera. En la misma medida al poder reflexionar sobre sus dificultades, los estudiantes transforman el curso de su accionar y se preparan internamente para abordar las actividades con un menor nivel de ansiedad y mayor apertura que los lleve a avanzar en su competencia comunicativa.

Bajo estas premisas queda como tarea de los profesores aplicar estrategias metacognitivas e ir capacitando a los alumnos para que alcancen la verdadera significatividad en el aprendizaje por medio de la autorregulación y la metacognición. 


\section{Referencias bibliográficas}

ALLIENDE, F. Y CONDEMARÍN, M. (1994). La lectura: teoría, evaluación y desarrollo. Santiago de Chile: Editorial Andrés Bello.

ANDERSON, A Y LYNCH, T. (2003). Lstening. New York: Oxford University Press.

ARÉVALO, J. (2016). Diseño de la Unidad Curricular Electiva: Comprensión Auditiva. Coro: UNEFM.

BERKO, R., WOLVIN, A., WOLVIN, D., Y AITKEN, J. (2016). Communicating: A social, career and cultural focus. New York: Routledge.

BROWN, D. (2007). Teaching by Principles: An Interactive Approach to Language Pedagogy. England: Longman

BROWN, D. (2014). Principles of language learning and teaching. England: Longman

BROWN, G. (2017). Listening to spoken English. New York: Routledge.

CHOMSKY, N. (2006). Language and Mind. Nueva York: Cambridge University Press.

CAMPO, K., ESCORCIA, D., MORENO, M. Y PALACIO, J. (2016). «Metacognición escritura y rendimiento académico en universitarios de Colombia y Francia». Avances en psicología latinoamericana. Vol 34 (2): 233-252

CÓRDOBA, P., COTO, R. y RAMÍREZ, M. (2005). «La comprensión auditiva: definición, importancia, características, procesos, materiales y actividades». Actualidades Investigativas en Educación. Vol 5, $\mathrm{N}^{\circ}$ 1: 1-17

ESCORCIA, D. (2010). «Conocimientos metacognitivos y autorregulación: Una lectura cualitativa del funcionamiento de los estudiantes universitarios en la producción de textos». Avances en Psicología Latinoamericana. Vol. 28(2): 265-277.

GALVIN, K. (1988). Listening by Doing: Developing Effective Listening Skills. Lincolnwood: National Textbook Company.

GILAKJANI, A. Y SABOURI, N. (2016). “Learners' listening comprehension difficulties in English language learning. A literature review". English language teaching, 9(6): 123.

GOH, C. (2018). “Metacognition in second language listening”. The TESOL encyclopedia of English language teaching: 1-7

HARMER, J. (2008). How to teach English. México: McGraw-Hill.

HARMER, J. (2015). The practice of English language teaching. England: Longman group. 
HERNÁNDEZ, J. E IZQUIERDO, J. (2016). “Metacognición y comprensión oral en L2: Observación de la práctica docente en el nivel universitario". Revista electrónica de investigación educativa. 18 (1): 39-52.

KRASHEN, S. (2009)."The comprehension hypothesis extended". En Piske, T. y YoungScholten, M. (Eds). Input matters in SLA. (pp. 81-94). Bristol, England: Multilingual Matters.

LEE, J. (2018). “Comprehensible input”. The TESOL encyclopedia of English language teaching: 1-7.

RICHARDS, J. AND SCHMIDT, R. (2013). Longman dictionary of language teaching and applied linguistcs. New York: Routledge.

ROST, M. (2011). Teaching and Researching Listening. London: Pearson-Longman.

SCHMIDT, N. (2013). An introduction to applied linguistics. Londres: Routledge.

UR, P. (2013). Teaching listening comprehension. Cambridge: Cambridge university press.

WOLVIN, A. (2010). Listening and human communication in the 21st century. Oxford: Blackwell Publishing. 